\title{
Viral-bacterial coinfection affects the presentation and alters the prognosis of severe community-acquired pneumonia
}

\author{
Guillaume Voiriot ${ }^{1,7^{*}}$, Benoit Visseaux², Johana Cohen ${ }^{1}$, Liem Binh Luong Nguyen ${ }^{3}$, Mathilde Neuville', \\ Caroline Morbieu ${ }^{3}$, Charles Burdet ${ }^{3}$, Aguila Radjou', François-Xavier Lescure ${ }^{3}$, Roland Smonig ${ }^{1}$, \\ Laurence Armand-Lefèvre ${ }^{4}$, Bruno Mourvillier ${ }^{1}$, Yazdan Yazdanpanah ${ }^{3,5}$, Jean-Francois Soubirou' ${ }^{1}$ Stephane Ruckly ${ }^{6}$, \\ Nadhira Houhou-Fidouh ${ }^{2}$ and Jean-François Timsit, ${ }^{1,5}$
}

\begin{abstract}
Background: Multiplex polymerase chain reaction (MPCR) enables recovery of viruses from airways of patients with community-acquired pneumonia (CAP), although their clinical impact remains uncertain.

Methods: Among consecutive adult patients who had undergone a mPCR within 72 hours following their admission to one intensive care unit (ICU), we retrospectively included those with a final diagnosis of CAP. Four etiology groups were clustered: bacterial, viral, mixed (viral-bacterial) and no etiology. A composite criterion of complicated course (hospital death or mechanical ventilation $>7$ days) was used. A subgroup analysis compared patients with bacterial and viral-bacterial CAP matched on the bacterial pathogens.
\end{abstract}

Results: Among 174 patients (132 men [76\%], age 63 [53-75] years, SAPSII 38 [27;55], median PSI score 106 [78;130]), bacterial, viral, mixed and no etiology groups gathered 46 (26\%), 53 (31\%), 45 (26\%) and 30 (17\%) patients, respectively. Virus-infected patients displayed a high creatine kinase serum level, a low platelet count, and a trend toward more frequent alveolar-interstitial infiltrates. A complicated course was more frequent in the mixed group $(31 / 45,69 \%)$, as compared to bacterial $(18 / 46,39 \%)$, viral $(15 / 53,28 \%)$ and no etiology $(12 / 30,40 \%)$ groups $(p<0.01)$. In multivariate analysis, the mixed (viral-bacterial) infection was independently associated with complicated course (reference: bacterial pneumonia; $\mathrm{OR}, 3.58 ; \mathrm{Cl} 95 \%, 1.16-11 ; p=0.03$ ). The subgroup analysis of bacteria-matched patients confirmed these findings.

Conclusions: Viral-bacterial coinfection during severe CAP in adults is associated with an impaired presentation and a complicated course.

Keywords: Pneumonia, Viral pneumonia, Respiratory viruses, Intensive care

\section{Background}

Community-acquired pneumonia (CAP) is a common disease that may become severe, leading to admission to intensive care units (ICU) [1]. CAP etiology is usually bacterial; however, the causative role of respiratory viruses emerged recently [2]. Multiplex polymerase chain

\footnotetext{
* Correspondence: guillaume.voiriot@aphp.fr

${ }^{1}$ Service de Réanimation Médicale et Infectieuse, Hôpital Bichat Claude Bernard, Hôpitaux Universitaires Paris Nord Val de Seine, Assistance Publique - Hôpitaux de Paris (AP-HP), Paris, France

${ }^{7}$ Hôpital Bichat Claude Bernard, 46 rue Henri Huchard, Paris 75018, France

Full list of author information is available at the end of the article
}

reaction (mPCR) kits screen a large panel of respiratory viruses, and nowadays are available in clinical practice. They were used within several studies among adult ICU patients with CAP [3-6]. High rates of positivity were reported, up to $49 \%$ [4], with strong variations in the distribution of viral species according to the population, the season, and the geographic area. However, the causative role of respiratory viruses identified in the respiratory tract during pneumonia is still debatable, since respiratory viruses might be present in asymptomatic adult subjects $[7,8]$. Some experimental data focusing on virus-bacteria interactions during respiratory 
tract infections supported a pathogenic role of respiratory viruses during pneumonia [9]. In mice, the coinfection of influenza with S. pneumoniae [10], L. pneumophila [11] or $S$. aureus [12] impaired the anti-influenza immune response and increased the mortality. Similar synergistic results are obtained with $S$. pneumoniae and respiratory syncytial virus [13], or S. pneumoniae and rhinovirus [14].

In humans, the pathogenic role of respiratory viruses in virus-bacteria coinfected patients remains unclear. We conducted a comprehensive observational study among adult ICU patients with CAP, to compare clinical characteristics, biological presentation, and outcome according to the presence of virus in the respiratory tract.

\section{Methods}

\section{Study design and patient selection}

We conducted a retrospective monocenter observational study in the 26-bed ICU of the Bichat Claude Bernard University Hospital (Paris, France). During the study period, all consecutive patients having undergone a MPCR in the respiratory tract within the 72 hours following their ICU admission were screened. Medical records were independently reviewed by two physicians. All patients with a final diagnosis of pneumonia were included (see definitions for population selection in Additional file 1).

\section{Data collection}

AT ICU admission and during ICU stay, data regarding demographics, comorbidity, clinical examinations, laboratory and radiological findings, microbiologic investigations, and therapeutic management were collected (for details, see Additional file 1). Mortality was defined as death from any cause within 30 days of hospitalization.

Pneumonia severity was assessed through the Pneumonia Severity Index (PSI) [15], and the Simplified Acute Physiologic Score (SAPS) II [16].

\section{Microbiological evaluation}

Respiratory tract specimens underwent Gram staining and quantitative culture for bacterial pathogens. Urine antigen testing of S. pneumoniae and L. pneumophila used the BinaxNOW kits (Alere, Jouy en Josas, France). The immunoglobulin (Ig) antibodies testing for C. pneumoniae and $M$. pneumoniae was considered positive if IgM antibodies were identified or if a significant increase in IgG antibodies was observed between paired serum samples.

The respiratory $\mathrm{mPCR}$ were performed either in nasopharyngeal (NP) swabs or in lower respiratory tract (LRT) specimens, usually bronchoalveolar lavage fluid otherwise endotracheal aspirate. During the study period, different mPCR kits were used (for details, see Additional file 1). Respifinder 19 (Pathofinder, Maastricht, The Netherlands) and Filmarray Respiratory Panel
(BioFire Diagnostics, Salt Lake City, UT, USA) could not detect bocavirus nor differentiate rhinovirus and enterovirus; therefore, rhinovirus and enterovirus results were grouped as picornavirus (rhinovirus).

Either in blood samples or in bronchoalveolar lavage fluid, the cytomegalovirus PCR used the CMV R-gene ${ }^{\circ}$ kit (Argene, Verniolle, France ) or the $\mathrm{QS}^{-\mathrm{RGQ}^{\circ}}$ kit (Qiagen, Hilden, Germany), and the herpex simplex virus PCR used LightCycler ${ }^{\circledR}$ HSV (Roche, Basel, Switzerland).

\section{Classification of patients according to pathogens}

A bacterium was considered as a causative pathogen of the pneumonia if this bacterium fulfilled at least one criterion (for details, see Additional file 1). A virus identified with PCR was always considered as a causative pathogen of the pneumonia.

Pneumonia was defined as: (i) bacterial, if microbiological investigations revealed at least one bacterium and no virus; (ii), viral, if microbiological investigations revealed at least one virus and no bacterium; (iii) mixed (virus-bacteria), if microbiological investigations revealed at least one virus and one bacterium; and (iv) no etiology, if microbiological investigations revealed no virus and no bacterium.

\section{Endpoints}

The primary endpoint was to identify presentation and prognosis-specific features in virus-bacteria coinfected patients. Comparisons focused on microbiological data, biological findings and radiological patterns on admission, ICU course and hospital outcome. A composite criterion named "complicated course" included hospital death or mechanical ventilation for more than 7 days. The second endpoint was to describe the epidemiology of respiratory viruses in adult patients admitted to the ICU for a CAP. Patients were clustered into four groups according to the microbiological etiology of pneumonia: bacterial, viral, mixed, and no etiology.

\section{Matching procedure}

To better control for impact of the bacterial pathogen on our main findings, we also designed a subgroup analysis comparing patients with bacterial and mixed viralbacterial CAP, matched on the bacterial pathogen. If more than one bacterium was identified in cases, we sought for a control with the same bacterial combination.

\section{Data presentation and statistical analysis}

Continuous data were expressed as median [first through third quartiles] and were compared using the Kruskall-Wallis test followed by pairwise Mann-Whitney test. Categorical data were expressed as number (percentages) and were evaluated using the chi-square test or Fisher's exact test. $p$ values less than 0.05 were 
considered significant. A univariate logistic regression with clinically relevant variables was used to identify variables associated with a complicated course. A multivariate conditional logistic regression, including variables with $p$ value less than 0.10 in the previous step, was used to identify variables independently associated with complicated course. Similar statistical analyses were performed to identify variables independently associated with hospital death and mechanical ventilation for more than 7 days in survivors at day 28. Quantitative variables that did not validate the log-linearity assumption were transformed into categorical variable according to their median value. Missing data were imputed to the median or to the more frequent value. The accuracy of the final model was tested using area under the receiver operating characteristic curve analysis and the Hosmer-Lemeshow chi-square test. An additional multivariate conditional logistic regression, limited to bacterial and mixed groups, was performed to search specifically for an association between virus-bacteria coinfection and complicated course. Comparisons in the subgroup analysis of bacteriamatched patients involved univariate conditional logistic regression followed by multivariate conditional logistic regression to assess associations between microbiological diagnosis and complicated course, adjusting for clinically relevant variables. Analyses were performed using the SAS software package (SAS Institute, Cary, NC, USA).

\section{Results}

\section{Population}

From October 2011 to June 2015, 752 patients were screened (Fig. 1). The final study group consisted of 174 patients (132 men (76\%), age 63 [53-75] years, SAPS II 38 [27;55]) (Table 1). One third (33.3\%) were referred from medical wards or another ICU. The median PSI score at hospital admission was 106 [78;130]. Pneumonia was considered health care-associated pneumonia in nearly half the patients $(49.4 \%)$. At least one factor of immunosuppression was present in $32.8 \%$ of patients.

\section{Microbiological diagnosis}

The microbiological investigations are displayed in Additional file 1: Table S1. The microbiological findings are displayed in Table 2. mPCR was performed in NP swabs exclusively $(\mathrm{n}=110,63.2 \%)$ or in LRT specimen exclusively ( $n=43,24.7 \%)$ or both $(n=21, n=13.2 \%)$. Respiratory tract specimens for bacterial culture have been obtained in 153 (87.9\%) patients. In 34 (19.5\%) patients the only respiratory tract specimen that has been obtained was sputum. Near half the patients $(n=77$, $44.3 \%)$ received antibiotics prior to referral.

A microbiological documentation was obtained in 144 $(82.8 \%)$ patients. At least one bacterium was identified in 91 (52.3\%) patients and at least one virus in 98
(56.3\%) patients. Bacterial documentation was obtained in $56(57.7 \%)$ patients who had not been exposed to antibiotics prior to referral, compared to 35 (45.5\%) antibiotics-exposed patients $(p=0.13)$. S. pneumoniae was the most commonly identified bacterium, found in 40 (23\%) patients. Of these 40 patients, S. pneumoniae was cultured in blood in five patients. In 22 (12.6 \%) patients, more than one bacterial species was identified. Taken together, Pseudomonas aeruginosa and Enterobacteriaceae species were identified in nine $(19.5 \%)$ patients of the bacterial group and nine (19\%) patients of the mixed group.

Influenza viruses and picornavirus (rhinovirus) were the most commonly identified viruses, found in 38 (21.8\%) and 22 (12.6\%) patients, respectively. In nine (5.2\%) patients, more than one virus was identified. In the 21 patients having undergone mPCR in both NP swabs and LRT specimen, the mPCR were discordant in ten patients, including eight patients with a NP MPCR positive and a LRT mPCR negative and two patients with a NP mPCR negative and a LRT MPCR positive.

\section{Analysis according the microbiological diagnosis}

The four study groups did not differ in terms of demographics, comorbid conditions, chronic immunosuppression, HCAP factors, incidence of transfer from another ward, and antibiotics before referral (Table 1). The microbiological investigations also were similar (Additional file 1: Table S1). S. pneumoniae was the predominant bacterium in both bacterial and mixed groups (Table 2). Only one patient was infected with extended-spectrum betalactamase-producing Enterobacteriaceae. Fourteen patients were infected with intracellular bacteria, including L. pneumophila, C. pneumoniae and M. pneumoniae, but only two had a viral coinfection. Influenza viruses were the most commonly viruses in the viral group, whereas picornavirus (rhinovirus) and influenza viruses were equally predominant in the mixed group.

The incidence of shock was higher in patients with a documented bacterial infection (30.4\% and $24.4 \%$ in bacterial and mixed group, respectively) in comparison with other patients $(5.7 \%$ and $13.3 \%$ in viral and no etiology groups, respectively, $p<0.01$ ) (Table 1 ). Overall, patients with mixed pneumonia displayed a higher disease severity on hospital and ICU admission, with higher rate of PSI class IV-V at hospital referral (80\% vs. $67.4 \%, 62.3 \%$ and $46.7 \%$ in bacterial, viral, and no etiology groups, respectively, $p=0.03$ ) and increased SAPS II (46 vs 39, 36 and 33 in bacterial, viral, and no etiology groups, respectively, $p=0.02$ ).

Among the 45 patients with mixed pneumonia, 30 were infected with viruses other than influenza, including 14 patients infected with picornavirus (rhinovirus). 


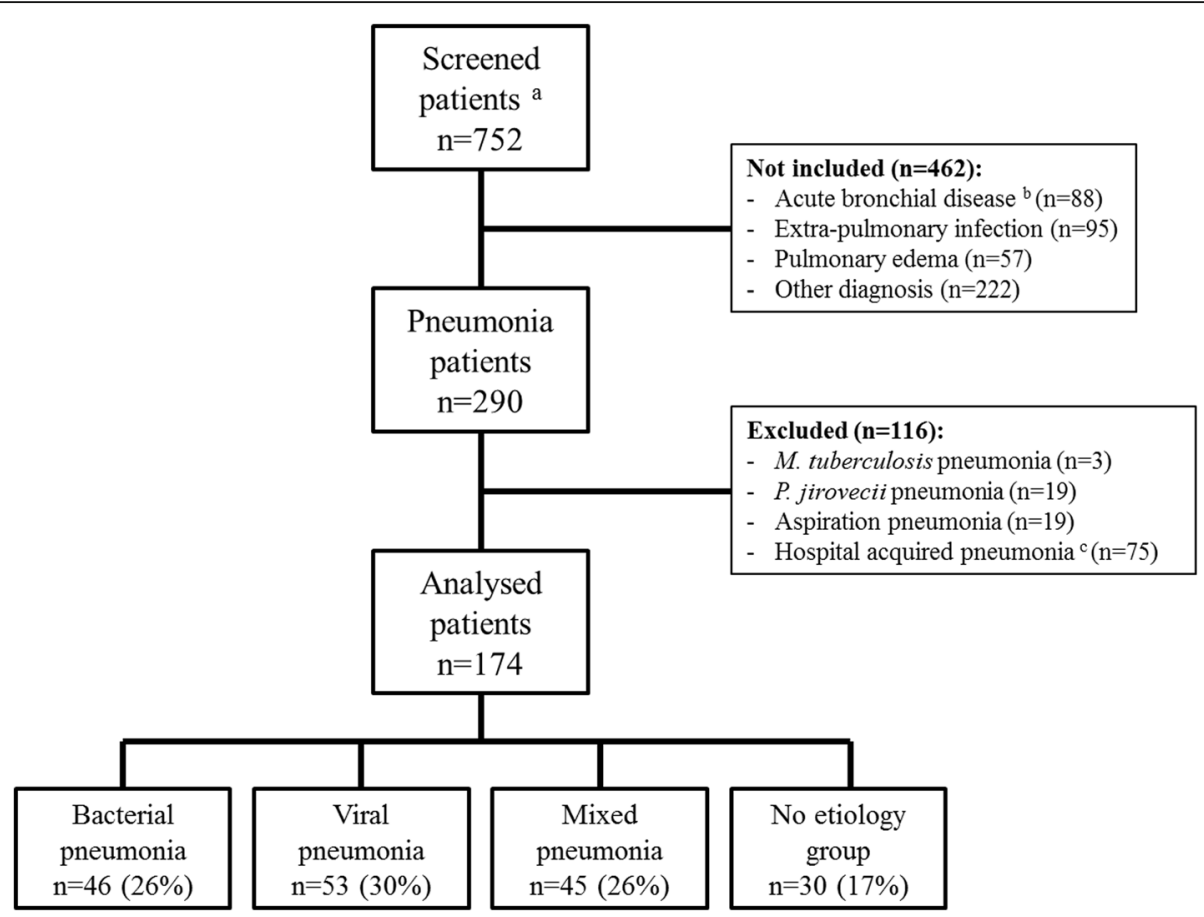

Fig. 1 Flow chart. a All consecutive patients admitted to the ICU during a 3.5-year period and having undergone a mPCR on a respiratory tract sample within 72 hours following ICU admission were screened. b Acute bronchial disease included COPD exacerbation, asthma, and acute bronchitis. c Pneumonia was considered hospital-acquired if neither clinically present nor in an incubation period at time of hospital admission

Virus-infected patients displayed high serum levels of creatine kinase, a low platelet count and a trend toward a high incidence of alveolar-interstitial infiltrates on chest X-ray (Additional file 1: Table S2). No significant difference was observed between groups regarding cardiac troponin T. However, 20 (20.4 \%) virus-infected patients displayed a cardiac troponin $\mathrm{T}$ above the upper limit of normal, compared to eight (10.5\%) virusuninfected patients.

All the bacteria-infected patients, except one in the bacterial group (45/46, $97.8 \%$ ) and one in the mixed group (44/45, $97.8 \%)$, received an appropriate antimicrobial regimen within the first 24 hours of ICU admission. Among the influenza-infected patients, most patients (32/ $38,84.2 \%)$ received ozeltamivir within the first 24 hours of admission to ICU. Complicated course was more frequent in the mixed group $(31 / 45,68.9 \%)$, as compared to bacterial $(18 / 46,39.1 \%)$, viral $(15 / 53,28.3 \%)$, and no etiology $(12 / 30,40 \%)$ groups $(p<0.01)$. In multivariate analysis, the microbiological diagnosis was identified as an independent factor of complicated course (Table 3). The microbiological diagnosis was not independently associated with hospital death (Additional file 1: Table S3) but with mechanical ventilation for more than 7 days in survivors at day 28 (Additional file 1: Table S4). The additional multivariate analysis, limited to bacterial and mixed groups, identified the virus-bacteria coinfection as independently associated with the complicated course (reference: bacterial pneumonia; OR, 3.56; CI $95 \%$, 1.24-10.18; $p=0.02$ ) (Table 4). The impact of the viral coinfection was similar for influenza and other viruses (Additional file 1: Table S5). The subgroup analysis of bacteria-matched patients confirmed these findings (Additional file 1: Table S6).

\section{Discussion}

This retrospective study investigated the impact of the mixed viral-bacterial coinfection on the presentation and outcome of ICU patients with CAP. Real-time mPCR tests identified at least one virus in the respiratory tract of $56.3 \%$ of patients. Specific biological and radiographic features, including high serum levels of creatine kinase, a low platelet count, and a high incidence of alveolarinterstitial infiltrates were observed in these patients, who presented also the higher status severity on hospital admission and the higher frequency of hemodynamic and respiratory failures during ICU stay. The viralbacterial coinfection was independently associated with a complicated course. These findings were confirmed by a subgroup analysis comparing bacteria-infected and virus-bacteria coinfected patients.

In this study, more than one patient out of two $(56.3 \%)$ were infected with at least one virus, in line with a recent report on ICU ventilated patients with CAP [4]. This finding illustrated the high yield of an aggressive diagnostic strategy with a broad panel mPCR 
Table 1 Baseline characteristics, behavior during ICU stay, and outcome of 174 patients with severe CAP, according to the microbiological diagnosis

\begin{tabular}{|c|c|c|c|c|c|c|}
\hline Patients & $\begin{array}{l}\text { All patients } \\
(\mathrm{n}=174)\end{array}$ & $\begin{array}{l}\text { Bacterial group } \\
(n=46)\end{array}$ & $\begin{array}{l}\text { Viral group } \\
(n=53)\end{array}$ & $\begin{array}{l}\text { Mixed group } \\
(n=45)\end{array}$ & $\begin{array}{l}\text { No etiology group } \\
(n=30)\end{array}$ & $p$ value $^{a}$ \\
\hline Age, y & $63[53 ; 75]$ & $64[53 ; 75]$ & $64[54 ; 75]$ & $63[54 ; 75]$ & $66[57 ; 78]$ & 0.85 \\
\hline Sex, male & $132(75.9)$ & $37(80.4)$ & $38(71.7)$ & $33(73.3)$ & $24(80)$ & 0.69 \\
\hline Weight, kg & $71[62 ; 82]$ & $70[60 ; 80]$ & $71[64 ; 84]$ & $70[60 ; 77]$ & $75[62 ; 83]$ & 0.64 \\
\hline Smoking & $53(31.7)$ & $16(37.2)$ & $16(30.8)$ & $13(30.2)$ & $8(27.6)$ & 0.83 \\
\hline McCabe score > 1 & $38(21.8)$ & $7(15.2)$ & $13(24.5)$ & $12(26.7)$ & $6(20)$ & 0.56 \\
\hline WHO performance status $>0$ & $53(33.5)$ & $10(22.7)$ & $19(41.3)$ & $14(35.9)$ & $10(34.5)$ & 0.30 \\
\hline Chronic immunosuppression & $57(32.8)$ & $16(34.8)$ & $21(39.6)$ & $14(31.1)$ & $6(20)$ & 0.32 \\
\hline HIV & $14(8)$ & $7(15.2)$ & $3(5.7)$ & $3(6.7)$ & $1(3.3)$ & 0.20 \\
\hline Steroid therapy & $19(10.9)$ & $2(4.3)$ & $10(18.9)$ & $6(13.3)$ & $1(3.3)$ & 0.06 \\
\hline Other immunosuppressive & $21(12.4)$ & $3(6.5)$ & $10(20)$ & $7(15.6)$ & $1(3.4)$ & 0.08 \\
\hline Solid organ transplantation & $14(8)$ & $2(4.3)$ & $5(9.4)$ & $6(13.3)$ & $1(3.3)$ & 0.31 \\
\hline Cancer & $15(8.6)$ & $6(13)$ & $4(7.5)$ & $2(4.4)$ & $3(10)$ & 0.51 \\
\hline Chronic disease $^{\mathrm{b}}$ & $86(49.4)$ & $20(43.5)$ & $34(64.2)$ & $20(44.4)$ & $12(40)$ & 0.08 \\
\hline Coronary artery disease & $27(15.5)$ & $6(13)$ & $9(17)$ & $9(20)$ & $3(10)$ & 0.64 \\
\hline $\mathrm{HCAP}^{\mathrm{C}}$ & $86(49.4)$ & $22(47.8)$ & $31(58.5)$ & $22(48.9)$ & $11(36.7)$ & 0.29 \\
\hline Transfer from another ward ${ }^{d}$ & $58(33.3)$ & $14(30.4)$ & 19 (35.8) & $17(37.8)$ & $8(26.7)$ & 0.72 \\
\hline Antibiotics before ICU admission ${ }^{e}$ & $77(44.3)$ & $15(32.6)$ & $30(56.6)$ & $19(42.2)$ & $13(43.3)$ & 0.12 \\
\hline \multicolumn{7}{|l|}{ Organ failures on ICU admission } \\
\hline Glasgow $<15$ & $42(24.1)$ & $14(30.4)$ & $11(20.8)$ & $11(24.4)$ & $6(20)$ & 0.66 \\
\hline Shock & $32(18.4)$ & $14(30.4)$ & $3(5.7)$ & $11(24.4)$ & $4(13.3)$ & $<0.01$ \\
\hline $\mathrm{PaO}_{2} / \mathrm{FIO}_{2}$ ratio & $174[130 ; 230]$ & $173[130 ; 229]$ & $172[122 ; 227]$ & $165[134 ; 228]$ & $200[165 ; 252]$ & 0.22 \\
\hline SAPS II score & $38[27 ; 55]$ & $39[32 ; 60]$ & $36[26 ; 48]$ & $46[34 ; 59]$ & $33[18 ; 46]$ & 0.02 \\
\hline PSI score at hospital referral & $106[78 ; 130]$ & $110[84 ; 152]$ & $98[82 ; 128]$ & $119[98 ; 126]$ & $89[70 ; 121]$ & 0.12 \\
\hline PSI class IV-V at hospital referral & $114(65.5)$ & $31(67.4)$ & $33(62.3)$ & $36(80)$ & $14(46.7)$ & 0.03 \\
\hline \multicolumn{7}{|l|}{ Organ supports during ICU stay } \\
\hline Noninvasive ventilation & $55(31.8)$ & $14(30.4)$ & $21(40.4)$ & $12(26.7)$ & $8(26.7)$ & 0.44 \\
\hline Mechanical ventilation & $98(56.3)$ & $28(60.9)$ & $22(41.5)$ & $36(80)$ & $12(40)$ & $<0.01$ \\
\hline ARDS & $60(34.5)$ & $17(37)$ & $13(24.5)$ & $22(48.9)$ & $8(26.7)$ & 0.06 \\
\hline Dialysis & $37(21.3)$ & $10(21.7)$ & $10(18.9)$ & $12(26.7)$ & $5(16.7)$ & 0.72 \\
\hline Vasopressors & $80(46.2)$ & $22(47.8)$ & $19(36.5)$ & $27(60)$ & $12(40)$ & 0.12 \\
\hline \multicolumn{7}{|l|}{ Outcome } \\
\hline Length of mechanical ventilation, $d$ & $9[5 ; 13]$ & $6.5[3 ; 12.5]$ & $7[4 ; 12]$ & $9[6 ; 14]$ & $10[7.5 ; 17.5]$ & 0.34 \\
\hline Follow-up duration, $\mathrm{d}^{\mathrm{f}}$ & $15[10 ; 29]$ & $14[5 ; 23]$ & $18[12 ; 32]$ & $16[11 ; 31]$ & $14.5[12 ; 19]$ & 0.25 \\
\hline Hospital mortality & $30(17.2)$ & $6(13)$ & $6(11.3)$ & $13(28.9)$ & $5(16.7)$ & 0.10 \\
\hline Complicated course $^{g}$ & $74(42.5)$ & $18(39.1)$ & $15(28.3)$ & $31(68.9)$ & $10(33.3)$ & $<0.01$ \\
\hline
\end{tabular}

Data are presented as median [first through third quartiles] or number (\%)

ARDS acute respiratory distress syndrome, CAP community-acquired pneumonia; HCAP health care-associated pneumonia, HIV human immunodeficiency virus, ICU intensive care unit, PSI Pneumonia Severity Index, SAPS Simplified Acute Physiologic Score, WHO World Health Organization.

${ }^{a} p$ values refer to differences between bacterial, viral, mixed, and no etiology groups in univariate logistic regression

${ }^{\mathrm{b}}$ Chronic disease included chronic dialysis, mellitus diabetes requiring oral medication and/or insulin, chronic heart failure classified NYHA 3 or 4 , cirrhosis, chronic respiratory failure requiring long-term oxygen therapy, and chronic immunosuppression

'Pneumonia was considered health care-associated (HCAP) in the presence of at least one of the following conditions: hospitalization for $\geq 2$ days in the preceding 90 days, institutionalization, chronic dialysis, and chronic immunosuppression

${ }^{\mathrm{d}}$ Transfer from another ward included transfers from another ICU and from the medical wards

${ }^{e}$ Antibiotics before ICU admission referred to any administration of antibiotics, whatever drug regimen, before the ICU referral, i.e., in emergency departments or in other medical wards

${ }^{f}$ The follow-up duration was defined as the time between the date of the mPCR and the date of hospital discharge. If the patient was deceased in hospital, the date of death was considered hospital discharge. If the patient was not deceased in hospital and the date of hospital discharge was not available, the date of ICU discharge was considered hospital discharge ${ }^{9}$ Complicated course was defined as hospital death and/or mechanical ventilation $>7$ days 
Table 2 Microbiological findings of 174 patients with severe CAP

\begin{tabular}{|c|c|c|c|c|c|}
\hline Patients & $\begin{array}{l}\text { All patients } \\
(n=174)\end{array}$ & $\begin{array}{l}\text { Bacterial group } \\
(n=46)\end{array}$ & $\begin{array}{l}\text { Viral group } \\
(n=53)\end{array}$ & $\begin{array}{l}\text { Mixed group } \\
(n=45)\end{array}$ & $\begin{array}{l}\text { No etiology group } \\
(n=30)\end{array}$ \\
\hline S. pneumoniae & $40(23)$ & $19(41.3)$ & - & $21(46.7)$ & - \\
\hline Other streptococci & $6(3.4)$ & $2(4.3)$ & - & $4(8.9)$ & - \\
\hline S. aureus & $12(6.9)$ & $6(13)$ & - & $6(13.3)$ & - \\
\hline L. pneumophila & $8(4.6)$ & $7(15.2)$ & - & $1(2.2)$ & - \\
\hline C. pneumoniae - M. pneumoniae & $6(3.4)$ & $5(10.9)$ & - & $1(2.2)$ & - \\
\hline H. influenzae & $13(7.5)$ & $5(10.9)$ & - & $8(17.8)$ & - \\
\hline Enterobacteriaceae species & $11(6.3)$ & $7(15.2)$ & - & $4(8.9)$ & - \\
\hline$P$. aeruginosa & $7(4)$ & $2(4.3)$ & - & $5(11.1)$ & - \\
\hline Other bacteria & $3(1.7)$ & $1(2.2)$ & - & $2(4.4)$ & - \\
\hline Mixed flora & $10(5.7)$ & $6(13)$ & - & $4(8.9)$ & - \\
\hline Picornavirus (rhinovirus) ${ }^{\mathrm{a}}$ & $22(12.6)$ & - & $7(13.2)$ & $15(33.3)$ & - \\
\hline Influenza A & $32(18.4)$ & - & 19 (35.8) & $13(28.9)$ & - \\
\hline Influenza B & $6(3.4)$ & - & $4(7.5)$ & $2(4.4)$ & - \\
\hline Parainfluenza & $3(1.7)$ & - & $2(3.8)$ & $1(2.2)$ & - \\
\hline Respiratory syncytial virus & $9(5.2)$ & - & $5(9.4)$ & $4(8.9)$ & - \\
\hline Human metapneumovirus & $12(6.9)$ & - & $6(11.3)$ & $6(13.3)$ & - \\
\hline Coronavirus & $14(8)$ & - & $7(13.2)$ & $7(15.6)$ & - \\
\hline Adenovirus & $3(1.7)$ & - & $2(3.8)$ & $1(2.2)$ & - \\
\hline Bocavirus & $1(0.6)$ & - & $1(1.9)$ & $0(0)$ & - \\
\hline Cytomegalovirus & $1(0.6)$ & - & $1(1.9)$ & $0(0)$ & - \\
\hline Herpes simplex virus & $3(1.7)$ & - & $1(1.9)$ & $2(4.4)$ & - \\
\hline Varicella zoster virus & $1(0.6)$ & - & $1(1.9)$ & $0(0)$ & - \\
\hline
\end{tabular}

Data are presented as number (\%)

CAP community-acquired pneumonia

${ }^{\text {a }}$ icornavirus included rhinovirus and enterovirus

on respiratory tract specimens. Elsewhere, the rate of viral documentation reported in adult ICU patients with CAP was slightly lesser, from 23 to $49 \%$ [3-5].

Respiratory tract specimens for bacterial test were recovered in a high proportion of patients (87.9 \%),

Table 3 Multivariate analysis of the risk factors for complicated course in 174 patients with severe CAP

\begin{tabular}{llll}
\hline Variables & OR & $95 \% \mathrm{Cl}$ & $p$ value \\
\hline Microbiological diagnosis & & & \\
$\quad$ Bacterial pneumonia & Ref & $\ldots$ & \\
$\quad$ Viral pneumonia & 0.69 & $0.24-1.95$ & 0.48 \\
Mixed pneumonia & 3.15 & $1.12-8.83$ & 0.03 \\
$\quad$ No etiology pneumonia & 1.29 & $0.40-4.21$ & 0.67 \\
Coronary artery disease & 3.52 & $1.22-10.15$ & 0.02 \\
Shock on ICU admission & 4.63 & $1.56-13.74$ & 0.006 \\
Lactate dehydrogenase $>$ 245 U/L & 4.27 & $1.55-11.78$ & 0.005 \\
PSI class IV-V at hospital referral & 4.67 & $1.96-11.12$ & 0.0005 \\
\hline
\end{tabular}

CAP community-acquired pneumonia, ICU intensive care unit, $O R$ odds ratio, PSI Pneumonia Severity Index, Ref reference, $95 \% \mathrm{Cl}=95 \%$ confidence interval including a LRT specimen in $68.4 \%$ of patients. Bacterial documentation was obtained in $52.3 \%$ of patients, in the range of other studies on ICU patients with CAP (36-82 \%) [3, 4]. Interestingly, the rate of bacteremia, $6.3 \%$, was markedly lower than usually observed $[17,18]$; it might be attributable to a high pre-referral exposure to antibiotics (44.3\%). Overall, $82.8 \%$ of patients had a

Table 4 Risk factors for complicated course in patients with severe CAP: multivariate analysis exploring the 91 patients with either bacterial or mixed viral-bacterial infection

\begin{tabular}{llll}
\hline Variables & OR & $95 \% \mathrm{Cl}$ & $p$ value \\
\hline Microbiological diagnosis & & & \\
$\quad$ Bacterial pneumonia & Ref & $\ldots$ & \\
$\quad$ Mixed pneumonia & 3.56 & $1.24-10.18$ & 0.02 \\
Coronary artery disease & 2.59 & $0.60-11.19$ & 0.20 \\
Shock on ICU admission & 5.63 & $1.53-20.73$ & 0.009 \\
Lactate dehydrogenase > 245 U/L & 5.16 & $1.49-17.90$ & 0.01 \\
PSI class IV-V at hospital referral & 2.69 & $0.76-9.51$ & 0.13
\end{tabular}

$C A P$ community-acquired pneumonia, ICU intensive care unit, Ref reference, $O R$ odds ratio, PSI Pneumonia Severity Index, $95 \%$ Cl $95 \%$ confidence interval 
microbiological diagnosis, a high rate in line with that of Karhu and colleagues [4].

The predominant viruses were influenza viruses and picornavirus (rhinovirus) (21.8\% and $12.6 \%$, respectively). Previous studies in ICU patients with CAP reported a much lower rate of influenza infection, from 2 to $10 \%$ [3-6]. It might be explained by low influenza vaccine coverage in our population. Unfortunately, the influenza vaccination history was usually not available in medical records, preventing any conclusion on this point. The incidence of rhinovirus was consistent with that of previous reports $[3,5]$. Interestingly, a "viral phenotype" is emerging, mainly characterized by high serum levels of creatine kinase, and high frequency of alveolar-interstitial infiltrates on chest X-ray. It was not yet reported, since previous works having largely used mPCR in ICU patients with CAP did not specifically record biology and radiographic data [3-6]. Chest X-ray patterns, notably ground glass opacities, were consistent with previous data [19]. Elevated levels of serum creatine kinase could be attributable to the rhabdomyolysis associated with viral infections, especially with influenza and parainfluenza viruses [20]. The trend toward a high serum level of cardiac troponin $\mathrm{T}$ in virus-infected patients might suggest acute myocardial injury. Furthermore, alveolar-interstitial infiltrates could indicate pulmonary edema. Unfortunately, brain natriuretic peptide dosage and echocardiogram data were not available, although left ventricular dysfunction has been previously described in influenza A infection [21].

Virus-bacteria coinfection was observed in one patient out of four, consistently with previous reports (9-39\%) $[3,4,22]$. It was identified as independently associated with a complicated course. This finding is original, since previous works that studied CAP patients requiring ICU admission did not point out any relationship between viral-bacterial coinfection and severity [3, 4]. Karhu and colleagues studied a limited cohort $(\mathrm{n}=49)$, whereas Choi and colleagues observed a low rate of virusbacteria coinfected patients in their cohort (18/198, $9 \%$ ), thus preventing any analysis on outcome in both studies. In hospitalized patients with CAP, some data suggested that the viral-bacterial coinfection might be associated with high-risk classes of PSI [23], higher length of hospital stay [24], and higher mortality [25]. More specifically, S. pneumoniae-influenza and S. pneumoniae-rhinovirus coinfections were correlated with a more severe illness in hospitalized patients [22, 26, 27]. In our study, in order to avoid overinterpreting the data, we decided to consider respiratory viruses as a homogeneous group of pathogens. This might be criticized, since the pathogenicity probably differs from one viral species to another. However, our results remained similar when taking into account non-influenza viruses only.
Further studies with larger populations may explore this point, with comparing the prognosis of CAP patients according to the type of virus as well as the different virus-bacteria combinations. Our findings might have a therapeutic impact. Currently, only very few medications targeting non-influenza respiratory viruses are available in clinical practice (cidofocir, ribavirine, immunoglobulins). But some novel antiviral drugs, targeting mainly respiratory syncytial virus and parainfluenza virus, have shown promising results in immunocompromised patients [28, 29] and in human volunteers [30]. Whether these upcoming drugs would be of interest in virusinfected CAP patients requiring ICU admission is questionable. We identified the virus-bacteria coinfected patients to be at risk of complicated ICU course, so further studies might explore potential benefits of the upcoming antiviral drugs in this high-risk population.

Our study has several limitations. First, this is a monocenter study, so the generalization of our results should be cautious. Second, this study included patients with pneumonia that required ICU admission. It means that we did not study mild to moderate pneumonia, preventing any conclusion on this population. Third, the study was retrospective so we did not control the microbiological investigations. By definition, a mPCR was performed in the respiratory tract of every included patient because it was the criteria for patient screening. But some other microbiological testings were only occasionally performed, i.e. cytomegalovirus and herpes simplex virus PCR, or C. pneumoniae and $M$. pneumoniae antibodies testing. Furthermore, the retrospective design prevented us obtaining a number of data, which were rarely reported in medical records by physicians, including vaccine history, symptoms before hospital referral, and duration of symptoms before ICU admission. Fourth, only patients having undergone a MPCR in the respiratory tract within the 72 hours following their ICU admission were screened; this might suggest a confounding of indication. Fifth, we chose a composite endpoint, decided a priori. Indeed, considering the predictable low hospital mortality, we did not choose hospital death as primary endpoint, because the low frequency of the event (death) would have favored the absence of significant difference between groups. Sixth, we made the assumption that a virus identified with PCR was a causative pathogen of the pneumonia. This might be criticized since respiratory viruses might be present in asymptomatic adult subjects $[7,8]$. Seventh, almost half the patients $(\mathrm{n}=77,44.3 \%)$ received antibiotics prior to ICU admission. Thus some patients may have had false-negative findings regarding bacterial infection and may have been falsely included in the viral group instead of the mixed group or to the no etiology group instead of the bacterial group. 


\section{Conclusions}

Viruses are frequently identified in the respiratory tract of patients with pneumonia requiring ICU admission, with a strong predominance of influenza and rhinovirus. The viral-bacterial coinfection concerns more than a quarter of patients and is associated with an impaired radiological and biological presentation and with a complicated course.

\section{Additional file}

Additional file 1: Table S1. Microbiological investigations performed in 174 patients with severe CAP. Table S2. Initial biological findings and radiological patterns of 174 patients with severe CAP, according to the microbiological diagnosis. Table S3. Multivariate analysis of the risk factors for hospital death in 174 patients with severe CAP. Table S4. Multivariate analysis of the risk factors for mechanical ventilation for more than 7 days in survivors at day 28. Table S5. Baseline characteristics, behavior during ICU stay, and outcome of 45 patients with mixed infection, according to the viral diagnosis. Table S6. Baseline characteristics, initial biological findings and radiological patterns, ICU course and outcome in bacteria-matched patients with severe CAP. (DOCX $39 \mathrm{~kb})$

\section{Abbreviations}

ARDS: acute respiratory distress syndrome; AST: aspartate aminotransferase; CAP: community-acquired pneumonia; Cl: confidence interval; COPD: chronic obstructive pulmonary disease; HCAP: health care-associated pneumonia; HIV: human immunodeficiency virus; ICU: intensive care unit; Ig: immunoglobulin; LRT: lower respiratory tract; $\mathrm{MPCR}$ : multiple polymerase chain reaction; NP: nasopharyngeal; OR: odds ratio; PSI: Pneumonia Severity Index; Ref: reference; SAPS II: Simplified Acute Physiology Score; WHO: World Health Organization

\section{Acknowledgements}

The authors are very grateful to the Assistance Publique - Hôpitaux de Paris (AP-HP) for their participation to the publication costs.

\section{Funding}

None.

\section{Availability of data and materials}

Data and materials supporting the findings of this study can be shared on request.

\section{Authors' contribution}

GV had full access to all of the data in the study and takes responsibility for the integrity of the data and the accuracy of the data analysis, including and especially any adverse effects. GV participated in the design of the study, participated in the data acquisition, analysis and interpretation, the statistical analysis, and drafted the manuscript. BV participated in the design of the study, participated in the data acquisition, analysis and interpretation, and helped to revise the manuscript. JC participated in the data acquisition, analysis and interpretation, and helped to draft the manuscript. LBLN participated in the data acquisition, analysis and interpretation, and helped to draft the manuscript. MN participated in the data analysis and interpretation, and helped to revise the manuscript. CM participated in the data acquisition, and helped to draft the manuscript. CB participated in the data analysis and interpretation, and helped to revise the manuscript. AR participated in the data analysis and interpretation, and helped to revise the manuscript. FXL participated in the data analysis and interpretation, and helped to revise the manuscript. RS participated in the data analysis and interpretation, and helped to revise the manuscript. LAL participated in the data acquisition, analysis and interpretation, and helped to draft the manuscript. BM participated in the data analysis and interpretation, and helped to revise the manuscript. YY participated in the data analysis and interpretation, and helped to revise the manuscript. JFS participated in the data analysis and interpretation, and helped to revise the manuscript. SR participated in the data analysis and interpretation, the statistical analysis, and helped to draft the manuscript. $\mathrm{NH}$ participated in the design of the study, participated in the data analysis and interpretation, and helped to revise the manuscript. JFT designed the study, participated in the data analysis and interpretation, the statistical analysis, and revised the manuscript. All authors read and approved the final manuscript.

\section{Authors' information}

Not applicable.

\section{Competing interests}

The authors have reported that no potential conflicts of interest exist with any companies/organizations whose products or services may be discussed in this article.

\section{Consent for publication}

Not applicable.

\section{Ethics approval and consent to participate}

This study was approved by the institutional review board (Comité d'Evaluation de l'Ethique des projets de Recherche Biomédicale, CEERB Paris Nord) according to the French regulations. The board waived the need for signed consent for patients included in the study.

\section{Author details}

${ }^{1}$ Service de Réanimation Médicale et Infectieuse, Hôpital Bichat Claude Bernard, Hôpitaux Universitaires Paris Nord Val de Seine, Assistance Publique - Hôpitaux de Paris (AP-HP), Paris, France. ${ }^{2}$ Service de Virologie, Hôpital Bichat Claude Bernard, Hôpitaux Universitaires Paris Nord Val de Seine, Assistance Publique - Hôpitaux de Paris (AP-HP), Paris, France. ${ }^{3}$ Service de Maladies Infectieuses et Tropicales, Hôpital Bichat Claude Bernard, Hôpitaux Universitaires Paris Nord Val de Seine, Assistance Publique - Hôpitaux de Paris (AP-HP), Paris, France. ${ }^{4}$ Service de Microbiologie, Hôpital Bichat Claude Bernard, Hôpital Bichat Claude Bernard, Hôpitaux Universitaires Paris Nord Val de Seine, Assistance Publique - Hôpitaux de Paris (AP-HP), Paris, France. ${ }^{5}$ Université Paris Diderot-Paris VII, Paris, France. ${ }^{6}$ Université de Grenoble 1, Center U823 Epidemioloy of Cancers and Severe Diseases, La Tronche, France. ${ }^{7}$ Hôpital Bichat Claude Bernard, 46 rue Henri Huchard, Paris 75018, France.

Received: 17 May 2016 Accepted: 29 September 2016

Published online: 25 October 2016

\section{References}

1. Prina E, Ranzani OT, Torres A. Community-acquired pneumonia. Lancet. 2015:386(9998):1097-108.

2. Ruuskanen O, Lahti E, Jennings LC, Murdoch DR. Viral pneumonia. Lancet. 2011;377(9773):1264-75

3. Choi S-H, Hong S-B, Ko G-B, Lee Y, Park HJ, Park S-Y, et al. Viral infection in patients with severe pneumonia requiring intensive care unit admission. Am J Respir Crit Care Med. 2012;186(4):325-32.

4. Karhu J, Ala-Kokko TI, Vuorinen T, Ohtonen P, Syrjala H. Lower respiratory tract virus findings in mechanically ventilated patients with severe community-acquired pneumonia. Clin Infect Dis. 2014;59(1):62-70.

5. Wiemken T, Peyrani P, Bryant K, Kelley RR, Summersgill J, Arnold F, et al. Incidence of respiratory viruses in patients with community-acquired pneumonia admitted to the intensive care unit: results from the Severe Influenza Pneumonia Surveillance (SIPS) project. Eur J Clin Microbiol Infect Dis. 2013;32(5):705-10.

6. Cilloniz C, Ewig S, Ferrer M, Polverino E, Gabarrus A, Puig de la Bellacasa J, et al. Community-acquired polymicrobial pneumonia in the intensive care unit: aetiology and prognosis. Crit Care. 2011;15(5):R209.

7. Lieberman D, Shimoni A, Shemer-Avni Y, Keren-Naos A, Shtainberg R, Lieberman $\mathrm{D}$. Respiratory viruses in adults with community-acquired pneumonia. Chest. 2010;138(4):811-6.

8. Byington $\mathrm{CL}$, Ampofo K, Stockmann C, Adler FR, Herbener A, Miller T, et al. Community surveillance of respiratory viruses among families in the Utah Better Identification of Germs-Longitudinal Viral Epidemiology (BIG-LoVE) Study. Clin Infect Dis. 2015;61(8):1217-24.

9. McCullers JA. Insights into the interaction between influenza virus and pneumococcus. Clin Microbiol Rev. 2006;19(3):571-82. 
10. Blevins LK, Wren JT, Holbrook BC, Hayward SL, Swords WE, Parks GD, et al. Coinfection with Streptococcus pneumoniae negatively modulates the size and composition of the ongoing influenza-specific CD8(+) T cell response. J Immunol. 2014;193(10):5076-87.

11. Jamieson AM, Pasman L, Yu S, Gamradt P, Homer RJ, Decker T, et al. Role of tissue protection in lethal respiratory viral-bacterial coinfection. Science. 2013;340(6137):1230-4.

12. Iverson AR, Boyd KL, McAuley JL, Plano LR, Hart ME, McCullers JA. Influenza virus primes mice for pneumonia from Staphylococcus aureus. J Infect Dis. 2011;203(6):880-8.

13. Smith CM, Sandrini S, Datta S, Freestone P, Shafeeq S, Radhakrishnan P, et al. Respiratory syncytial virus increases the virulence of Streptococcus pneumoniae by binding to penicillin binding protein 1a. A new paradigm in respiratory infection. Am J Respir Crit Care Med. 2014;190(2):196-207.

14. Ishizuka S, Yamaya M, Suzuki T, Takahashi H, Ida S, Sasaki T, et al. Effects of rhinovirus infection on the adherence of Streptococcus pneumoniae to cultured human airway epithelial cells. J Infect Dis. 2003;188(12):1928-39.

15. Fine MJ, Auble TE, Yealy DM, Hanusa BH, Weissfeld LA, Singer DE, et al. A prediction rule to identify low-risk patients with community-acquired pneumonia. N Engl J Med. 1997;336(4):243-50.

16. Le Gall JR, Lemeshow S, Saulnier F. A new Simplified Acute Physiology Score (SAPS II) based on a European/North American multicenter study. JAMA. 1993;270(24):2957-63.

17. Laterre P-F, Garber G, Levy H, Wunderink R, Kinasewitz GT, Sollet J-P, et al. Severe community-acquired pneumonia as a cause of severe sepsis: data from the PROWESS study. Crit Care Med. 2005:33(5):952-61.

18. Voiriot G, Dury S, Parrot A, Mayaud C, Fartoukh M. Nonsteroidal antiinflammatory drugs may affect the presentation and course of community-acquired pneumonia. Chest. 2011;139(2):387-94.

19. Kim EA, Lee KS, Primack SL, Yoon HK, Byun HS, Kim TS, Suh GY, Kwon OJ, Han J. Viral pneumonias in adults: radiologic and pathologic findings. Radiographics. 2002;22 Spec No:S137-49.

20. Singh U, Scheld WM. Infectious etiologies of rhabdomyolysis: three case reports and review. Clin Infect Dis. 1996;22(4):642-9.

21. Martin SS, Hollingsworth CL, Norfolk SG, Wolfe CR, Hollingsworth JW. Reversible cardiac dysfunction associated with pandemic 2009 influenza A(H1N1). Chest. 2010:137(5):1195-7.

22. Jennings LC, Anderson TP, Beynon KA, Chua A, Laing RTR, Werno AM, et al. Incidence and characteristics of viral community-acquired pneumonia in adults. Thorax. 2008;63(1):42-8.

23. Templeton KE, Scheltinga SA, van den Eeden WCJFM, Graffelman AW, van den Broek PJ, Claas ECI. Improved diagnosis of the etiology of community-acquired pneumonia with real-time polymerase chain reaction. Clin Infect Dis. 2005:41(3):345-51.

24. Johansson N, Kalin M, Hedlund J. Clinical impact of combined viral and bacterial infection in patients with community-acquired pneumonia. Scand J Infect Dis. 2011;43(8):609-15.

25. Diederen BMW, Van Der Eerden MM, Vlaspolder F, Boersma WG, Kluytmans JAJW, Peeters MF. Detection of respiratory viruses and Legionella spp. by real-time polymerase chain reaction in patients with community acquired pneumonia. Scand I Infect Dis. 2009;41(1):45-50

26. Blyth CC, Webb SAR, Kok J, Dwyer DE, van Hal SJ, Foo H, et al. The impact of bacterial and viral co-infection in severe influenza. Influenza Other Respir Viruses. 2013;7(2):168-76.

27. Palacios G, Hornig M, Cisterna D, Savji N, Bussetti AV, Kapoor V, et al. Streptococcus pneumoniae coinfection is correlated with the severity of H1N1 pandemic influenza. PLoS One. 2009:4(12):e8540.

28. DeVincenzo J, Lambkin-Williams R, Wilkinson T, Cehelsky J, Nochur S, Walsh E, et al. A randomized, double-blind, placebo-controlled study of an RNAi-based therapy directed against respiratory syncytial virus. Proc Natl Acad Sci U S A. 2010:107(19):8800-5.

29. Guzman-Suarez BB, Buckley MW, Gilmore ET, Vocca E, Moss R, Marty FM, et al. Clinical potential of DAS181 for treatment of parainfluenza-3 infections in transplant recipients. Transpl Infect Dis. 2012;14(4):427-33.

30. DeVincenzo JP, Whitley RJ, Mackman RL, Scaglioni-Weinlich C, Harrison L, Farrell E, et al. Oral GS-5806 activity in a respiratory syncytial virus challenge study. N Engl J Med. 2014;371(8):711-22.

\section{Submit your next manuscript to BioMed Central and we will help you at every step:}

- We accept pre-submission inquiries

- Our selector tool helps you to find the most relevant journal

- We provide round the clock customer support

- Convenient online submission

- Thorough peer review

- Inclusion in PubMed and all major indexing services

- Maximum visibility for your research

Submit your manuscript at www.biomedcentral.com/submit

) Biomed Central 